\title{
Transient global amnesia: clinical features and prognostic factors suggesting recurrence
}

\author{
Amnesia global transitoria: características clínicas y factores pronósticos sugestivos de \\ recurrencia
}

\author{
Lucas Alessandro1, Ismael L. Calandri', Marcos Fernández Suarez², María L. Heredia², Hernán Chaves³, \\ Ricardo F. Allegri', Mauricio F. Farez ${ }^{4}$
}

\begin{abstract}
The risk of recurrence of new amnesia events in patients having previously experienced transient global amnesia (TGA) ranges between 2.9-23.8\%. Objective: Our objective was to search for recurrence predictors in TGA patients. Methods: Retrospective analysis to identify recurrence predictors in a cohort of 203 TGA patients from a single center in Buenos Aires, Argentina, diagnosed between January 2011 and March 2017. Clinical features and complementary studies (laboratory results, jugular vein Doppler ultrasound and brain MRI) were analyzed. Comparison between patients with recurrent versus single episode TGA was performed, applying a multivariate logistic regression model. Results: Mean age at presentation was 65 years (20-84); 52\% were female. Median time elapsed between symptom onset and ER visit was two hours, with the average episode duration lasting four hours. Mean follow-up was 22 months. Sixty-six percent of patients referred to an identifiable trigger. Jugular reflux was present in $66 \%$ of patients; and $22 \%$ showed images with hippocampus restriction on diffusionweighted MRI. Eight percent of patients had TGA recurrence. Patients with recurrent TGA had a more frequent history of migraine than patients without recurrence (37.5\% vs. $14 \% ; p=0.03$ ). None of the other clinical characteristics and complementary studies were predictors of increased risk of recurrence. Conclusions: Patients with migraine may have a higher risk of recurrent TGA. None of the other clinical characteristics evaluated allowed us to predict an increased risk of recurrence. Although the complementary studies allowed us to guide the diagnosis, they did not appear to have a significant impact on the prediction of recurrence risk.
\end{abstract}

Keywords: Amnesia, anterograde; recurrence; amnesia, transient global.

\section{RESUMEN}

El riesgo de recurrencia de nuevos eventos de amnesia en pacientes que han experimentado previamente Amnesia Global Transitoria (AGT) oscila entre el 2.9-23.8\%. Objetivo: Nuestro objetivo fue buscar predictores de recurrencia en pacientes con AGT. Métodos: Análisis retrospectivo de una cohorte de 203 pacientes con AGT de un único centro en Buenos Aires, Argentina, diagnosticados entre enero-2011 y marzo-2017. Se analizaron las características clínicas y los estudios complementarios (laboratorio, Doppler de vena yugular y RM encéfalo). Se comparó el grupo de AGT recurrente versus episodio único, aplicando un modelo de regresión logística multivariada. Resultados: la edad promedio de presentación fue de 65 años (20-84); 52\% mujeres. La mediana del tiempo transcurrido entre el inicio de los síntomas y la visita a la sala de emergencia fue de 2 horas, con una duración promedio del episodio de 4 horas. El seguimiento medio fue de 22 meses. $66 \%$ de los pacientes tuvieron un desencadenante identificable. El reflujo yugular estuvo presente en el $66 \%$ de los pacientes y el $22 \%$ mostró imágenes restrictivas en DWI a nivel hipocampal. $8 \%$ de los pacientes presentaron recurrencia. Los pacientes con AGT recurrente tuvieron un historial de migraña más frecuente (37.5\% vs. $14 \%$; $p=0.03$ ). Ninguna de las otras características clínicas y estudios complementarios fueron predictores de mayor riesgo de recurrencia. Conclusiones: los pacientes con migraña pueden tener un mayor riesgo de recurrencia de AGT. Ninguna de las otras características clínicas evaluadas nos permitió predecir un mayor riesgo de recurrencia. Aunque los estudios complementarios nos permitieron orientar el diagnóstico, no pareció tener un impacto significativo en la predicción del riesgo de recurrencia.

Palabras-clave: Amnesia anterógrada; recurrencia; amnesia global transitoria.

Transient global amnesia (TGA) is a syndrome characterized by sudden anterograde amnesia of less than 24 hours in duration, in the absence of other neurological symptoms. The annual TGA incidence is $3.4-10.4$ per $100,000^{1-4}$ increasing to 23.5 per 100,000 in individuals above the age of $50^{5}$. Many patients report Valsalva-associated maneuvers prior to TGA onset. Other trigger events identified were common everyday life activities, such as coughing or sexual intercourse.

${ }^{1}$ Raúl Carrea Institute for Neurological Research (FLENI), Department of Neurology, Buenos Aires, Argentina;

${ }^{2}$ Raúl Carrea Institute for Neurological Research (FLENI), Buenos Aires, Argentina;

${ }^{3}$ Department of Diagnostic Imaging, Raúl Carrea Institute for Neurological Research (FLENI), Department of Neurology, Buenos Aires, Argentina;

${ }^{4}$ Center for Research on Neuroimmunological Diseases (CIEN), Raúl Carrea Institute for Neurological Research (FLENI), Buenos Aires, Argentina.

Lucas Alessandro iD https://orcid.org/0000-0002-8597-8213

Correspondence: Lucas Alessandro; Raúl Carrea Institute for Neurological Research (FLENI); Montañeses 2325, Buenos Aires (1428), Argentina; E-mail: lalessandro@fleni.org.ar

Conflict of interest: There is no conflict of interest to declare.

Received 14 June 2018; Received in final form 17 September 2018; Accepted 17 October 2018. 
However, the general TGA recurrence rate remains low. According to published case series, TGA recurs in up to 2.9$23.8 \%$ of cases $^{3,6}$. To date, no information on potential factors explaining TGA recurrence is available, mainly due to a lack of understanding of TGA pathophysiology. More importantly, previous large TGA case series were published prior to 1990 , at which time the diagnostic criteria described by Caplan ${ }^{7}$, and later validated by Hodges and Warlow ${ }^{1}$, were not applied, nor were patient brain MRIs available, and CT scans had been performed in only a minority of the study individuals.

In this study, we describe the main clinical and demographic features of patients presenting with acute TGA, as well as relevant laboratory and imaging findings, applying current diagnostic criteria and using state-of-the-art neuroimaging technology. We also investigated potential predictors of TGA recurrence.

\section{METHODS}

A retrospective single center cohort study was conducted including patients presenting with TGA between January 2011 and March 2017. We identified 203 patients with TGA, diagnosed by applying Caplan's criteria ${ }^{7}$, validated by Hodges and Warlow ${ }^{1}$, who had been clinically evaluated within six hours of symptom onset. Diagnosis was established when the following criteria were met: 1) presence of anterograde amnesia witnessed by an observer; 2) no clouding of consciousness or loss of personal identity; 3) cognitive impairment limited to amnesia; 4) no focal neurological or epileptic signs; 5) no recent history of head trauma or seizures; 6) resolution of symptoms within 24 hours; and 7) mild vegetative symptoms (headache, nausea, dizziness), which may or may not be present during the acute phase.

Exclusion criteria included: presence of other neurological manifestations, past medical history of seizures, presence of brain tumor, and other major neurological or psychiatric diseases. During the acute event, clinical presentation, patient demographics and complementary studies (laboratory results, jugular vein Doppler ultrasound, brain CT and MRI, and electroencephalogram) were analyzed. The study had been approved by the Institutional Ethics Committee.

Demographic data (age, sex) and previous relevant clinical history (hypertension, dyslipidemia, current smoking, diabetes mellitus, previous stroke, coronary heart disease, atrial fibrillation, migraine and hypothyroidism) were collected. In addition, the characteristics of the first episode of amnesia (duration, season and time onset) were described. The following triggers were included: sexual intercourse, emotional stress, Valsalva maneuver, crying, coughing, defecation, bending down, weight lifting, exercise, vomiting, cold water immersion, hot bath, long trip and medication.

For jugular vein Doppler examination, a Xario SSA-660A ultrasound system (Toshiba Medical Systems Corp, Otawara,
Japan) was used. Every patient was examined at baseline and after a Valsalva maneuver, provoked by blowing into a mouthpiece attached to a manometer. Valvular insufficiency was defined as reflux lasting more than 0.8 seconds.

Electroencephalography (EEG) exploration was conducted using an ATI, Bioscience Stellate Harmonie, or a Philips Respironics Sleepware G3, both with 32-channel acquisition capacity. Electrodes were placed applying the 10-20 International System and signals acquired on monopolar montage and electronically reconverted to bipolar. Acquisition time was fixed at two hours. An examiner with a high proficiency in the field reviewed every EEG. The presence of either epileptiform activity or baseline rhythm disorganization, were considered abnormal.

High resolution diffusion-weighted images (DWI) (b = $1000 \mathrm{~s} / \mathrm{mm}^{2}, 3 \mathrm{~mm}$ slice thickness, $0 \mathrm{~mm}$ gap) were acquired on 1.5T Philips Achieva (Best, The Netherlands), 1.5T GE CVi, 1.5T GE Signa HDx, or 3T GE Signa HDxt (Milwaukee, WI, USA) scanners using 8-channel head coils. In order to increase MRI result specificity, only images obtained within 10 days of the TGA event were included in the analysis.

Recurrence of episodes were considered present when detected during the follow-up at our center, evaluated using the same methods described above. Moreover, we collected information on the occurrence of stroke, myocardial infarction and epileptic seizures after the first event of TGA.

Variables with non-normal distribution were evaluated using a nonparametric Mann-Whitney test; otherwise $t$-tests were performed to evaluate differences between groups. The Chi square or Fisher's exact test was used for categorical variables.

A cox proportional regression model was applied to estimate hazard ratios and 95\% confidence intervals using months of follow-up after initial TGA diagnosis as the timescale. A multivariate cox model was built in a forward fashion including variables with $\mathrm{p}$ values $<0.2$ in univariate analysis. We used Stata, version 12.1 software (Statacorp, USA), and 2-sided p values $<0.05$ were considered statistically significant.

\section{RESULTS}

A total of 203 patients were included for analysis; $8 \%$ of the patients had recurrent episodes. The mean age at presentation was 65 years (20-84 years); $52 \%$ were female. Median time to emergency room (ER) consult was two hours, with episodes lasting four hours on average; maximum time to recovery registered was 20 hours. All patients were followed for more than one year (mean 22 months), with most events occurring in the morning (46\%). Patients with recurrent TGA had a higher frequency of migraine ( $37.5 \%$ vs. $14 \%$; $\mathrm{p}=0.03$ ). There were no significant differences in other demographic or clinical characteristics between the groups with and without 
recurrence (Table 1). At follow-up, there were no differences between the two groups in the occurrence of stroke, acute myocardial infarction and epileptic seizure. Sixty-six percent of patients referred to a precipitating event for TGA; most often a Valsalva maneuver (41\%). No significant differences were found in precipitating events between groups (Table 2).
Laboratory test results at time of the ER visit during acute episodes were available in $77 \%$ of cases. The most common abnormalities encountered included: neutrophilia (35\%) and leukocytosis (14\%), although no cases of infection or malignancy were reported. Rates of significant electrolyte imbalance were extremely low (3\%) (hypophosphatemia $(\mathrm{n}=2)$,

Table 1. Selected baseline demographic and clinical characteristics of patients with nonrecurrent and recurrent transient global amnesia (TGA).

\begin{tabular}{|c|c|c|c|c|}
\hline Characteristics & All patients $(n=203)$ & Nonrecurrent TGA $(n=187)$ & Recurrent TGA $(n=16)$ & $p$-value* \\
\hline Age; median (range) & $65(20-84)$ & $65(20-84)$ & $65(48-80)$ & 0.7 \\
\hline Female; n (\%) & $105(52)$ & $97(52)$ & $8(50)$ & 0.9 \\
\hline \multicolumn{5}{|l|}{ Medical history, n (\%) } \\
\hline Hypertension & $103(52)$ & $93(51)$ & $10(62.5)$ & 0.5 \\
\hline Dyslipidemia & $108(54)$ & $98(54)$ & $10(62.5)$ & 0.7 \\
\hline Current smoking & $74(37)$ & $68(37)$ & $6(37.5)$ & 0.8 \\
\hline Diabetes mellitus & $13(6)$ & $13(7)$ & $0(0)$ & 0.6 \\
\hline Previous stroke & $14(7)$ & $13(7)$ & $1(6)$ & 0.9 \\
\hline Coronary heart disease & $16(8)$ & $15(8)$ & $1(6)$ & 1 \\
\hline Atrial fibrillation & $8(4)$ & $8(4)$ & $0(0)$ & 1 \\
\hline Migraine & $31(16)$ & $25(14)$ & $6(37.5)$ & 0.03 \\
\hline Hypothyroidism & $34(17)$ & $31(17)$ & $3(19)$ & 0.7 \\
\hline Stroke after TGA; n (\%) & $3(2)$ & $3(3)$ & $0(0)$ & 1 \\
\hline Acute myocardial infarction after TGA; n (\%) & $3(2)$ & $3(3)$ & $0(0)$ & 1 \\
\hline Epileptic seizure after TGA; n (\%) & 0 & 0 & 0 & - \\
\hline Duration in hours; median (range) & $4(0-20)$ & $4(0-20)$ & $3(0-18)$ & 0.08 \\
\hline Duration less than 1 hour; $\mathrm{n}(\%)$ & $21(10)$ & $3(19)$ & $18(10)$ & 0.2 \\
\hline \multicolumn{5}{|l|}{ Season of onset; $\mathrm{n}(\%)$} \\
\hline Summer & $50(25)$ & $45(24)$ & $5(31)$ & 0.8 \\
\hline Autumn & $46(23)$ & $43(23)$ & $3(19)$ & \\
\hline Winter & $41(20)$ & $39(21)$ & $2(12.5)$ & \\
\hline Spring & 66 (33) & $60(32)$ & $6(37.5)$ & \\
\hline Time of onset; $n(\%)$ & & & & 0.7 \\
\hline Morning & $90(46)$ & $84(47)$ & $6(40)$ & \\
\hline Noon & $25(13)$ & $23(13)$ & $2(13)$ & \\
\hline Afternoon & $56(29)$ & $50(28)$ & $6(40)$ & \\
\hline Evening & $23(29)$ & $22(12)$ & $1(7)$ & \\
\hline
\end{tabular}

${ }^{*}$ Chi square or Fisher's exact test (if cell value $\left.\leq 5\right)$ were used for categorical variables. Age and duration in hours were evaluated using a nonparametric MannWhitney test.

Table 2. Precipitating events for transient global amnesia (TGA).

\begin{tabular}{|c|c|c|c|c|}
\hline Precipitating events & All patients $(n=203)$ & Nonrecurrent TGA $(n=187)$ & Recurrent TGA $(n=16)$ & $p$-value* \\
\hline Has one or more precipitating event, $n$ (\%) & $129(66)$ & $118(66)$ & $11(73)$ & 0.5 \\
\hline Sexual intercourse, n (\%) & $22(11)$ & $20(11)$ & $2(12.5)$ & 0.7 \\
\hline Emotional stress, n (\%) & $47(23)$ & $41(22)$ & $6(37.5)$ & 0.3 \\
\hline Valsalva maneuver, n (\%) & $84(41)$ & $71(41)$ & $6(37.5)$ & 0.9 \\
\hline Crying, n (\%) & $3(1)$ & $3(2)$ & $0(0)$ & 1 \\
\hline Coughing, n (\%) & $6(3)$ & $5(3)$ & $1(7)$ & 0.4 \\
\hline Defecation, n (\%) & $15(7)$ & $14(7)$ & $1(6)$ & 1 \\
\hline Bending down, $\mathrm{n}(\%)$ & $2(1)$ & $2(1)$ & $0(0)$ & 1 \\
\hline Weight lifting, n (\%) & $1(0.5)$ & $1(1)$ & $0(0)$ & 1 \\
\hline Exercise, $n(\%)$ & $15(7)$ & $15(8)$ & $0(0)$ & 0.6 \\
\hline Vomiting, n (\%) & $4(2)$ & $4(2)$ & $0(0)$ & 1 \\
\hline Cold water immersion, n (\%) & $2(1)$ & $2(1)$ & $0(0)$ & 1 \\
\hline Hot bath, n (\%) & $22(11)$ & $21(11)$ & $1(6)$ & 1 \\
\hline Long trip, n (\%) & $4(2)$ & $4(2)$ & $0(0)$ & 1 \\
\hline Medication, n (\%) & $3(1)$ & $2(1)$ & $1(6)$ & 0.2 \\
\hline
\end{tabular}

* Chi square or Fisher's exact test (if cell value $\leq 5$ ). 
hypokalemia $(\mathrm{n}=1)$ and hypocalcemia $(\mathrm{n}=1)$. Jugular reflux was present in $66 \%$ of patients studied with Doppler $(n=123)$. Neuroimaging of the brain was performed on 192 patients (146 MRI and 46 CT); 104 were studied using a 1.5T scanner and 43 in a 3T scanner. Twenty-two percent of the cohort displayed diffusion restriction at the level of the hippocampi. Sixty-five percent of MRIs were performed within 24 hours of the earliest symptoms. Complementary studies did not appear to contribute to the prediction of risk of recurrence (Table 3).

We used a multivariable logistic regression model to investigate whether demographic characteristics, clinical, imaging or laboratory findings were predictors of TGA recurrence. None of the variables analyzed allowed us to predict which patients had a higher risk of recurrence.

\section{DISCUSSION}

Demographic and clinical characteristics of the study population were similar to those of other published series ${ }^{8-9}$. Patients with recurrent TGA had a more frequent history of migraine than patients without recurrence ( $37.5 \%$ vs. $14 \%$; $p=$ $0.03)$. No significant differences were found in the other variables analyzed between the groups (Table 1). Most events registered occurred during the morning hours, making transient epileptic amnesia a necessary differential diagnosis (more than one-third of cases occur on waking and up to $70 \%$ of patients have a crisis in this context $)^{10}$. The number of patients in which a specific trigger was recognized was $66 \%$, in agreement with previously-described series $(44-90 \%)^{8,11}$ (Table 2).

In contrast to certain reports of electrolyte imbalance as a possible cause of TGA, we found no evidence of major serological abnormalities, with the exception of a few cases of hypokalemia ${ }^{12}$. It is important to highlight the fact that a large number of patients in this study $(77 \%)$ were evaluated during the early hours of the event ( $<24$ hours), further supporting a lack of relationship between electrolyte imbalance and TGA. The early patient workups showed frequent neutrophilia. This finding has not been reported in any clinical case series to date. One possible explanation for this may be that this finding may represent a systemic response to psychological stressors caused by the amnesia episode $^{13}$. On the other hand, evidence linking neutrophils to ischemic brain processes has been described ${ }^{14-15}$, which may mean ischemia represents an indirect sign of mechanisms underlying TGA. However, no laboratory finding predicted recurrence (Table 3).

It has been previously suggested that internal jugular valve insufficiency contributes to TGA pathogenesis ${ }^{16}$. For this reason, patients with TGA are believed to be more prone to developing retrograde venous flow (Figure 1), as it is observed more often than in controls, or TIA patients ${ }^{17-18}$. However, no Doppler finding predicted TGA recurrence (Table 3).

Ischemic restrictive diffusion along the lateral hippocampus (mainly CA1) can be observed in up to $85 \%$ of patients using high-resolution MRI techniques (3T) $)^{19-20}$. In addition to image quality, the chances of finding ischemic lesions on DWI will depend on other parameters, such as the time elapsed between clinical symptom onset and MRI acquisition. Maximum detection levels were found within the first 48-72 hours $^{19}$. In this series, only $22 \%$ showed typical hippocampal lesions (Figure 2). This low detection rate on DWI may be explained in part because, in $65 \%$ of patients, MRIs were acquired within 24 hours of symptom onset. Other aspects to consider are: only a minority were evaluated in a 3T scanner and the $b$ value used for DWI was $1000 \mathrm{~s} / \mathrm{mm}^{2}$

Table 3. Clinical, laboratory and imaging findings in patients with transient global amnesia (TGA).

\begin{tabular}{|c|c|c|c|c|}
\hline Variable & All patients $(n=203)$ & Nonrecurrent TGA $(n=187)$ & Recurrent TGA $(n=16)$ & $p$-value* \\
\hline \multicolumn{5}{|l|}{ Laboratory findings; n (\%) } \\
\hline Hypoglycemia & 0 & 0 & 0 & - \\
\hline Altered ionogram & $4(3)$ & $4(3)$ & 0 & 1 \\
\hline Leukocytosis & $21(14)$ & $21(15)$ & 0 & 0.21 \\
\hline Neutrophilia & $52(35)$ & $48(35)$ & $4(31)$ & 1 \\
\hline \multicolumn{5}{|l|}{ EEG;n (\%) } \\
\hline Analyzed & $118(63)$ & $106(62)$ & $12(75)$ & 0.4 \\
\hline Altered & $1(0.5)$ & $0(0)$ & $1(6)$ & 0.09 \\
\hline \multicolumn{5}{|l|}{ Jugular Vein Doppler; n (\%) } \\
\hline Unilateral jugular reflux & $48(39)$ & $45(39)$ & $3(37.5)$ & 1 \\
\hline Bilateral jugular reflux & $33(27)$ & $30(27)$ & $3(37.5)$ & 0.7 \\
\hline Right jugular reflux & $72(59)$ & $67(59)$ & $5(62.5)$ & 1 \\
\hline Left jugular reflux & $48(40)$ & $44(39)$ & $4(50)$ & 0.7 \\
\hline \multicolumn{5}{|l|}{ MRI; n (\%) } \\
\hline Right hippocampus DWI restriction & $12(6)$ & $10(5)$ & $2(12.5)$ & 0.2 \\
\hline Left hippocampus DWI restriction & $14(7)$ & $12(6)$ & $2(12.5)$ & 0.3 \\
\hline Bilateral hippocampus DWI restriction & $5(2)$ & $5(3)$ & $0(0)$ & 1 \\
\hline
\end{tabular}

* Chi square or Fisher's exact test (if cell value $\leq 5$ )

EEG: electroencephalogram; DWI: Diffusion-weighted Magnetic Resonance Imaging; MRI: Magnetic resonance imaging. 


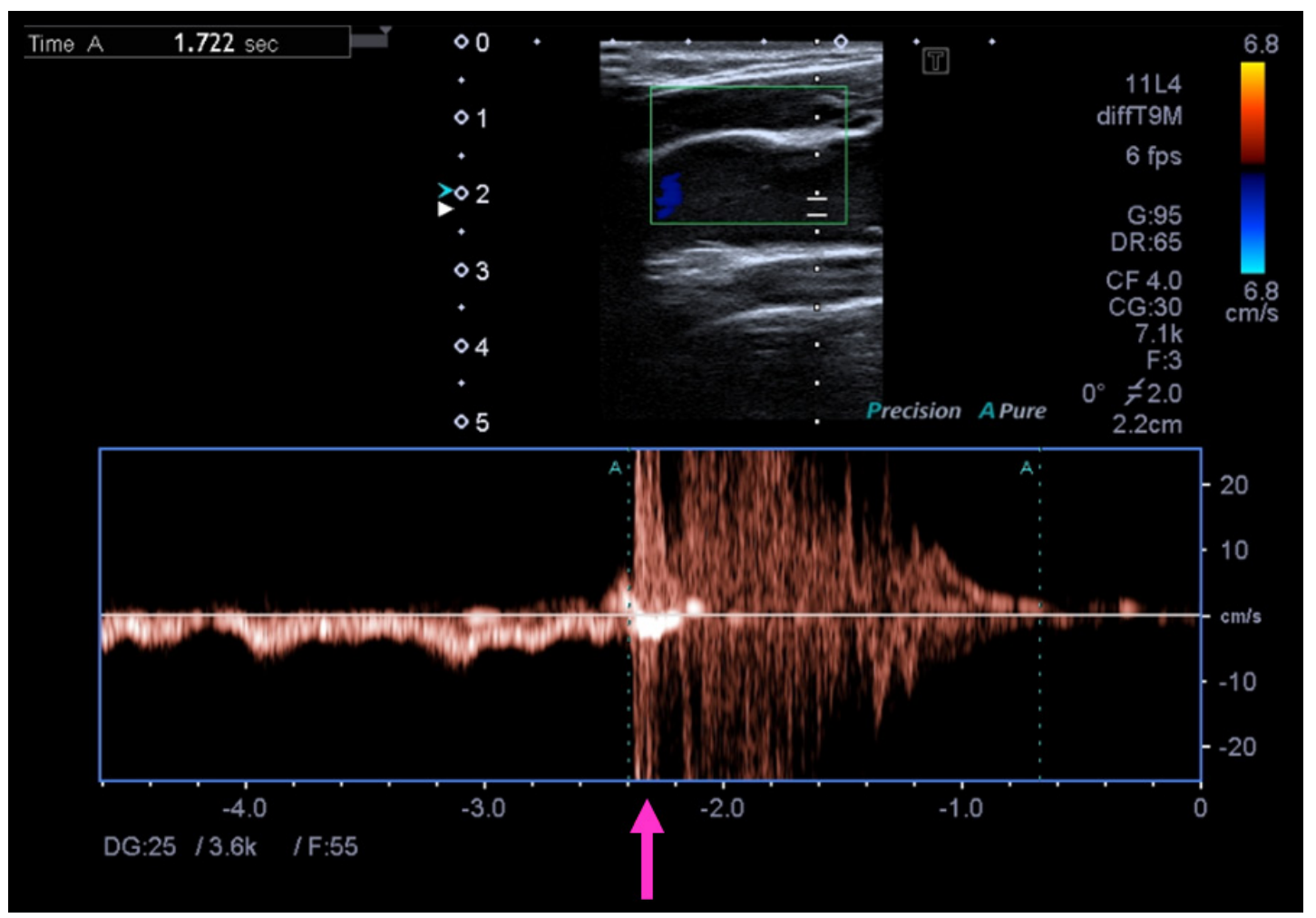

Figure 1. Doppler ultrasonography findings in transient global amnesia (TGA); arrow indicates reflux after Valsalva maneuver.
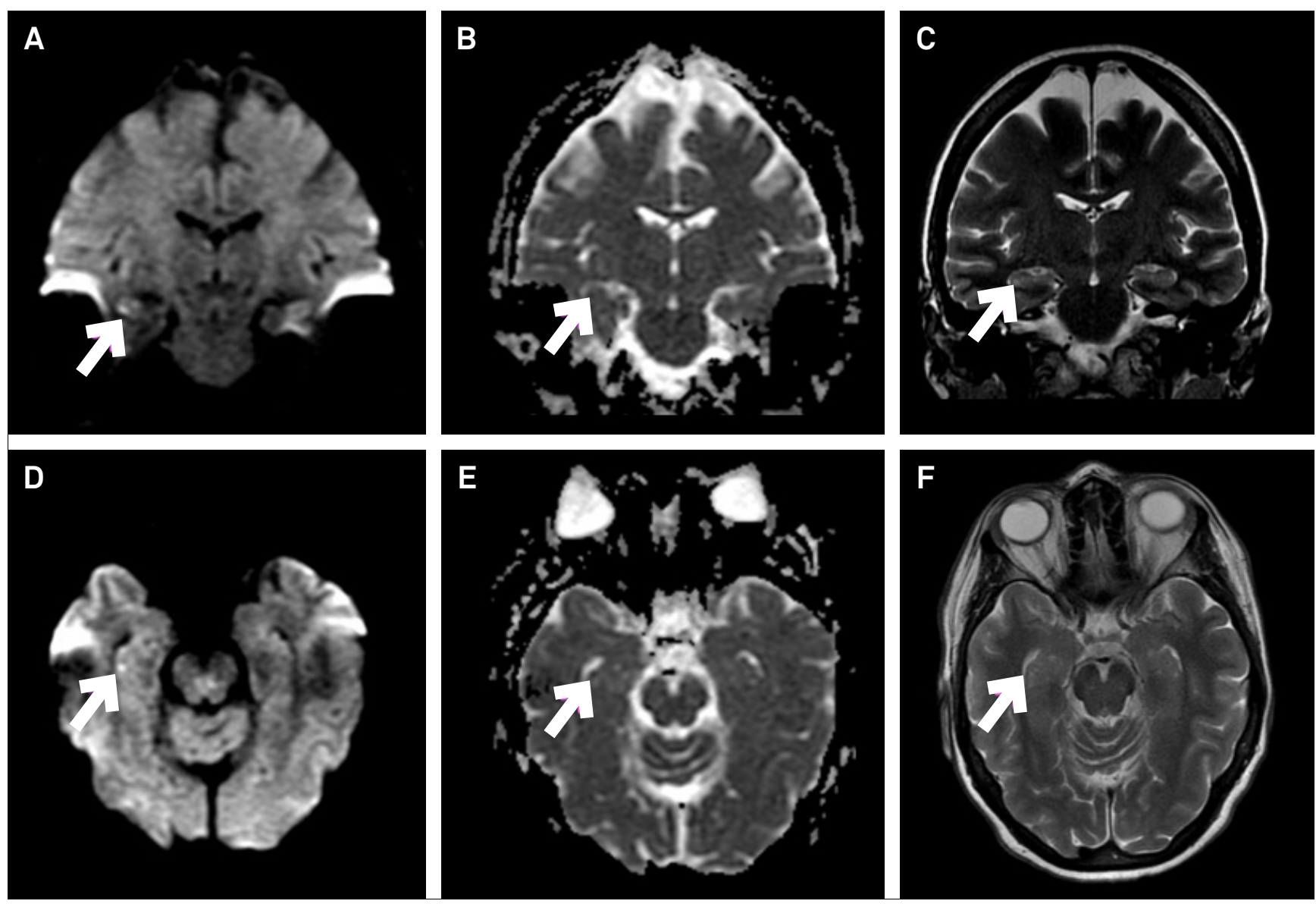

Figure 2. Diffusion-weighted imaging hyperintense lesions with apparent diffusion coefficient changes and T2 hyperintensity in two representative patients with transient global amnesia (TGA). 

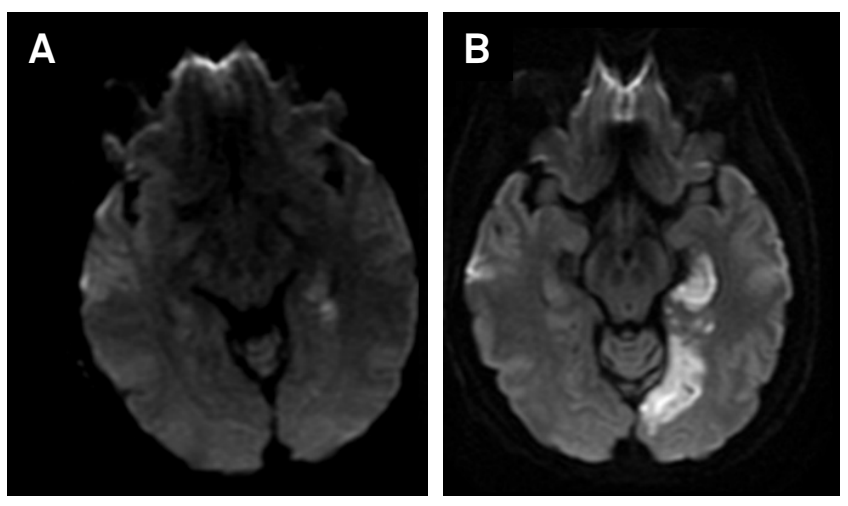

Figure 3. Patient with atrial myxoma with strategic stroke manifested as transient global amnesia (TGA). Hippocampus restriction on DWI within two hours of symptom onset (A), and after 24 hours (B).

(higher b values of $2000-3000 \mathrm{~s} / \mathrm{mm}^{2}$ have been reported to increase sensitivity ${ }^{20}$. Despite the above-mentioned limitations, a recent work describing a large series of patients evaluated at the Mayo Clinic, showed a low percentage of restrictive hippocampal images in DWI (4.26\%), similar to what we found in our population ${ }^{21}$. Although MRI was not useful for predicting recurrence (Table 3), it should not be excluded as a potentially useful study to predict recurrence. We found only one report describing that reversible DWI abnormalities are more frequent in patients with recurrent TGA. However, this was a work that included only 27 patients, with a higher percentage of recurrence (18\%) and that in none of the cases was the brain MRI performed during the first event of $\mathrm{TGA}^{22}$. However, although the Caplan and Hodges criteria are based solely on clinical parameters ${ }^{1,2,3,4,5,6,8}$, we believe that early brain MRI (< 24 hours) can help rule out other differential diagnoses, including strategic cerebrovascular accidents that can simulate TGA (Figure 3).

The recurrence rate was $8 \%$ in this series. We believe this percentage is highly specific as a result of the number of patients evaluated with neuroimaging (93\%), thus excluding patients with acute stroke in regions outside the hippocampus or structural lesions in memory-related areas (e.g. tumors, vascular malformations). Aside from this series, few articles have addressed the issue of TGA recurrence, with rates reported to be between 2.9 and $23.8 \%^{3,6,21,23,24,25,26}$. The references we allude to include between 51 and 277 patients. Only one study included a larger patient series, with a maximum follow-up of 82.5 months $^{3}$, and corresponds with a paper published prior to current TGA diagnostic criteria. The largest work, with results similar to ours, is the one recently described by the Mayo Clinic. However, it does not analyze possible risk factors that could explain the increased risk of recurrence after the first TGA event ${ }^{21}$.

The pathophysiological mechanisms of TGA remain uncertain. The main hypothesis involves passive hypoxia due to abnormal jugular drainage of the temporal lobes. For this reason, when there is an increase in intrathoracic pressure, as in the Valsalva maneuver, retrograde jugular flow occurs, which is responsible for the appearance of TGA ${ }^{15}$. On the other hand, it has been observed that patients with migraine have a greater risk of developing $\mathrm{TGA}^{27}$. In addition to this, migraineurs have decreased jugular venous distensibility $^{28}$ and increased reflux of the internal jugular vein during migraine attacks ${ }^{29}$. Our series supports these theories, as we observed that the Valsalva maneuver was the most frequent trigger of TGA and that jugular reflux, assessed by Doppler ultrasound, was present in two-thirds of the patients. However, jugular reflux would not be a sufficient condition to increase the risk of recurrence, but it could predominantly affect the population with migraine. Other proposed mechanisms involve phenomena similar to those produced in cerebral arterial ischemia ${ }^{30}$ or related to epilepsy ${ }^{31}$. The results of our series do not support either theory, nor do they appear to have an influence on the risk of recurrence.

Despite the high number of patients evaluated, we are aware that the size of the sample and the retrospective nature of the study may be insufficient to draw definitive conclusions.

In conclusion, the pathophysiological mechanisms responsible for producing TGA are still uncertain. This lack of knowledge could be part of the reason why it is difficult to find predictors of recurrence. However, the population with migraine may have a higher risk of recurrence. The complementary studies are useful to guide the diagnosis and rule out complementary diagnoses, although they were not enough to predict recurrence.

\section{References}

1. Hodges JR, Warlow CP. Syndromes of transient amnesia: towards a classification. A study of 153 cases. J Neurol Neurosurg Psychiatry. 1990 Oct;53(10):834-43. https://doi.org/10.1136/jnnp.53.10.834

2. Lauria G, Gentile M, Fasseta G, Casetta I, Caneve G. Incidence of transient global amnesia in the Belluno province, Italy: 1985 through 1995. Acta Neurol Scand. 1997;95(5):303-10. https://doi.org/10.1111/j.1600-0404.1997.tb00215.x

3. Miller JW, Petersen RC, Metter EJ, Millikan CH, Yanagihara T. Transient global amnesia: clinical characteristics and prognosis. Neurology. 1987 May;37(5):733-7. https://doi.org/10.1212/WNL.37.5.733
4. Koski KJ, Marttila RJ. Transient global amnesia: incidence in an urban population. Acta Neurol Scand. 1990 Apr;81(4):358-60. https://doi.org/10.1111/j.1600-0404.1990.tb01571.x

5. Miller JW, Yanagihara T, Petersen RC, Klass DW. Transient global amnesia and epilepsy. Electroencephalographic distinction. Arch Neurol. 1987 Jun;44(6):629-33. https://doi.org/10.1001/archneur.1987.00520180049015

6. Melo TP, Ferro JM, Ferro H. Transient global amnesia. A case control study. Brain. 1992 Feb;115(Pt 1):261-70. https://doi.org/10.1093/brain/115.1.261

7. Quinette P, Guillery-Girard B, Dayan J, de la Sayette V, Marquis S, Viader F, et al. What does transient global amnesia really mean? 
Review of the literature and thorough study of 142 cases. Brain. 2006 Jul;129(Pt 7):1640-58. https://doi.org/10.1093/brain/awl105

8. Bartsch T, Butler C. Transient amnesic syndromes. Nat Rev Neurol. 2013 Feb;9(2):86-97. https://doi.org/10.1038/nrneurol.2012.264

9. Butler CR, Zeman AZ. Recent insights into the impairment of memory in epilepsy: transient epileptic amnesia, accelerated long-term forgetting and remote memory impairment. Brain. 2008 Sep;131(Pt 9):2243-63. https://doi.org/10.1093/brain/awn127

10. Bartsch T, Alfke K, Stingele R, Rohr A, Freitag-Wolf S, Jansen O, et al. Selective affection of hippocampal CA-1 neurons in patients with transient global amnesia without long-term sequelae. Brain. 2006 Nov;129(Pt 11):2874-84. https://doi.org/10.1093/brain/awl248

11. Bermejo-Velasco PE, Castillo-Moreno L, Escamilla-Crespo C. [Transient global amnesia associated to hypopotassemia]. Rev Neurol. 2006;42(4):255-6. Spanish.

12. Kemeny ME, Schedlowski M. Understanding the interaction between psychosocial stress and immune-related diseases: a stepwise progression. Brain Behav Immun. 2007 Nov;21(8):1009-18. https://doi.org/10.1016/j.bbi.2007.07.010

13. Jin R, Yang G, Li G. Inflammatory mechanisms in ischemic stroke: role of inflammatory cells. J Leukoc Biol. 2010 May;87(5):779-89. https://doi.org/10.1189/jlb.1109766

14. Buck BH, Liebeskind DS, Saver JL, Bang OY, Yun SW, Starkman $S$ et al. Early neutrophilia is associated with volume of ischemic tissue in acute stroke. Stroke. 2008 Feb;39(2):355-60. https://doi.org/10.1161/STROKEAHA.107.490128

15. Lewis SL. Aetiology of transient global amnesia. Lancet. 1998 Aug;352(9125):397-9. https://doi.org/10.1016/S0140-6736(98)01442-1

16. Cejas C, Cisneros LF, Lagos R, Zuk C, Ameriso SF. Internal jugular vein valve incompetence is highly prevalent in transient global amnesia. Stroke. 2010 Jan;41(1):67-71. https://doi.org/10.1161/STROKEAHA.109.566315

17. Maalikjy Akkawi N, Agosti C, Anzola GP, Borroni B, Magoni M, Pezzini A et al. Transient global amnesia: a clinical and sonographic study. Eur Neurol. 2003;49(2):67-71. https://doi.org/10.1159/000068501

18. Sedlaczek O, Hirsch JG, Grips E, Peters CN, Gass A, Wöhrle J et al. Detection of delayed focal MR changes in the lateral hippocampus in transient global amnesia. Neurology. 2004 Jun;62(12):2165-70. https://doi.org/10.1212/01.WNL.0000130504.88404.C9

19. Weon YC, Kim JH, Lee JS, Kim SY. Optimal diffusion-weighted imaging protocol for lesion detection in transient global amnesia. AJNR Am J Neuroradiol. 2008 Aug;29(7):1324-8. https://doi.org/10.3174/ajnr.A1105
20. Arena JE, Brown RD, Mandrekar J, Rabinstein AA. Longterm outcome in patients with transient global amnesia: a population-based study. Mayo Clin Proc. 2017 Mar;92(3):399-405. https://doi.org/10.1016/j.mayocp.2016.11.015

21. Auyeung M, Tsoi TH, Cheung CM, Fong DY, Li R, Chan JK et al. Association of diffusion weighted imaging abnormalities and recurrence in transient global amnesia. J Clin Neurosci. 2011 Apr;18(4):531-4. https://doi.org/10.1016/j.jocn.2010.08.019

22. Zorzon M, Antonutti L, Masè G, Biasutti E, Vitrani B, Cazzato G. Transient global amnesia and transient ischemic attack. Natural history, vascular risk factors, and associated conditions. Stroke. 1995 Sep;26(9):1536-42. https://doi.org/10.1161/01.STR.26.9.1536

23. Pantoni L, Bertini E, Lamassa M, Pracucci G, Inzitari D. Clinical features, risk factors, and prognosis in transient global amnesia: a follow-up study. Eur J Neurol. 2005 May;12(5):350-6. https://doi.org/10.1111/j.1468-1331.2004.00982.x

24. Gandolfo C, Caponnetto C, Conti M, Dagnino N, Del Sette M, Primavera A. Prognosis of transient global amnesia: a long-term follow-up study. Eur Neurol. 1992;32(1):52-7. https://doi.org/10.1159/000116787

25. Klötzsch C, Sliwka U, Berlit P, Noth J. An increased frequency of patent foramen ovale in patients with transient global amnesia. Analysis of 53 consecutive patients. Arch Neurol. 1996 Jun;53(6):504-8. https://doi.org/10.1001/archneur.1996.00550060046014

26. Lin KH, Chen YT, Fuh JL, Li SY, Chen TJ, Tang CH, et al. Migraine is associated with a higher risk of transient global amnesia: a nationwide cohort study. Eur J Neurol. 2014 May;21(5):718-24. https://doi.org/10.1111/ene.12346

27. Chung CP, Chao AC, Hsu HY, Lin SJ, Hu HH. Decreased jugular venous distensibility in migraine. Ultrasound Med Biol. 2010 Jan;36(1):11-6. https://doi.org/10.1016/j.ultrasmedbio.2009.08.007

28. Chou CH, Fuh JL, Wang SJ, Hu HH, Wu JC, Cheng YT. Queckenstedt's test headache response is associated with increased jugular venous flow volume during migraine attack. Ultrasound Med Biol. 2011 Jan;37(1):23-8. https://doi.org/10.1016/j.ultrasmedbio.2010.10.018

29. Di Filippo M, Calabresi P. Ischemic bilateral hippocampal dysfunction during transient global amnesia. Neurology. 2007 Jul;69(5):493. https://doi.org/10.1212/01.wnl.0000271085.87627.72

30. Jacome DE. EEG features in transient global amnesia. Clin Electroencephalogr. $1989 \mathrm{Jul}$;20(3):183-92 https://doi.org/10.1177/155005948902000312 